\title{
Effect of Community Health Support Systems and Technology Obsolescence on Utilization of mHealth Information by Teenagers Living with HIV/AIDS in Island Communities of Lake Victoria, Kenya
}

Olan'g Alfred Philip Bill Okaka (Corresponding Author)

PhD Scholar, Development Studies, Jomo Kenyatta Universityof Agriculture and Technology, Kenya Email: onchaga@gmail.com

\section{Florence Ondieki - Mwaura}

Lecturer, Jomo Kenyatta University of Agriculture and Technology, Kenya

\author{
Maurice Sakwa \\ Lecturer, Jomo Kenyatta University of Agriculture and Technology, Kenya
}

\author{
Article History \\ Received: 19 April, 2021 \\ Revised: 17 June, 2021 \\ Accepted: 7 July, 2021 \\ Published: 11 July, 2021 \\ Copyright $(2021$ ARPG \& \\ Author \\ This work is licensed under \\ the Creative Commons \\ Attribution International \\ (क) 19
}

BY: Creative Commons Attribution License 4.0

\begin{abstract}
The emergence of mHealth as an alternative access point for care and treatment is lauded by development agencies as ingenious innovation for bridging health care access for teenagers living with HIV/AIDS among detached communities like the islands of Lake Victoria. It is also presumed that mHealth transcends beyond teenagers' concerns with location and unfriendly hours of operation of health facilities. mHealth is alleged to increase privacy and confidentiality, reduce the cost of service delivery, and loops over retrogressive cultural beliefs and attitudes exhibited by health care providers and caregivers, consequently increasing access to health information, care, and treatment. Specifically, the study sought to determine the technology obsolescence and explore community-based health support systems that facilitate suitable utilization of mHealth by teenagers living with HIV from the island communities of Lake Victoria and its effect on treatment access. To support this study, two philosophies: The theory of Reasoned Action and the Technology Adoption Lifecycle Model were applied. Anchored on cross-sectional study design, stratified sampling identified the psychosocial support groups of teenagers living with HIV. The probit model was applied to the study. With a study population of approximately 409 in Ringiti, Remba, Rusinga, Mfangano, and Mageta Islands, questionnaires were administered to 173 sampled teenagers living with HIV as a unit of analysis, and a control group made up of 30 percent of the sample ascertained effect of mHealth on treatment access. Five focus group discussions and key informant interviews of 10 and 3 were held on each Island. Multiple linear regression analysis was used to estimate the effect of the independent variables on the dependent variable. Further, the results showed that technology obsolescence and community-based health support systems had a significant effect on access to treatment by teenagers living with HIV/AIDS in the Island communities of Lake Victoria. Consequently, this study provides organizations promoting access to access to treatment by teenagers living with HIV/AIDS through mHealth. The study recommended that government and organizations involved in HIV/AIDS related activities should adopt a culture of enhancing mHealth by focusing on technology obsolescence and community-based health support systems. This could go a long way in ensuring there is improved access to treatment by teenagers living with HIV/AIDS in Island communities of Lake Victoria.
\end{abstract}

Keywords: M-health; Community support systems; Technology obsolescence; Teenagers; HIV/AIDS.

\section{Introduction}

Globally, seven billion people are covered by mobile-cellular network; 84 and 67 percent are in urban and rural respectively (International Telecommunication Union [ITU], 2016). Despite 75 percent of people in Africa being non-users (ITU, 2016), Kenya's mobile penetration was at 88.1 percent with 37.8 million subscribers (Communications Authority of Kenya [CAK], 2015). As mobile penetration hit the two-thirds mark in 2010 signifying a massive shift in the global digital commons (ITU, 2010), near-universal penetration is expected by 2020 (Banjanovic, 2009). Mobile phone has become an electronic wallet, the window to the World Wide Web, an education device, and more, and globally, mobile devices outnumber PCs, credit cards, and TVs (Lane, Isenberg, \& Knoop, 2007). The low-tech solution bridges the digital divide (Lane et al., 2007) as growth of mobile phones is outpacing communication through mass media (Chipchase et al., 2005).

Unlike non-smart phone text messaging (SMS) services, with 3G network, users of smart phones have increasing ability to create social change by access and broadcast of information. Thus, characterization of mobile phone handlers determines packaging and usability of information and Application Systems. Driven by market forces pegged on planned obsolescence in technology (LeBlanc et al., 2013), a paradigm shift to new age of digital literacy is realized. Notably are avatars, emoticons, pictures, sounds and videos that can hold more power than the bygone era of telephones where only names and numbers mattered (LeBlanc et al., 2013). Around 2010 to 2015, 
Sub-Saharan Africa (SSA) reigned as the world's fastest-growing mobile region, with subscriber growth rates more than twice the global average (The Mobile Economy sub-Sahara Africa [MESSA], 2015). The growth of 3G connections in SSA largely reflects the rising smartphone adoption rate, which has doubled in 2013 to 2015 , that is, to $20 \%$ of total connections (MESSA, 2015). In Kenya, mobile phones are becoming widespread with 42 subscriptions per 100 people in 2008 (CAK, 2015).

In Africa (Benin, Ghana, Senegal, South Africa, Tanzania, and Zambia), as opposed to general population, fishing communities have high HIV/AIDS prevalence rates (Kissling et al., 2005). Prevalence rates for fisherfolk were $20.3 \%$ in the Democratic Republic of Congo, 30.5\% in Kenya and 24.0\% in Uganda, representing 4.8, 4.5 and 5.8 times higher than in the general population respectively (Kissling et al., 2005). Moreover, in Kenya and Uganda, this incidence was 2.1 and 1.8 times respectively higher than truck drivers who use roads along the lake region. Rates of HIV infection are even slightly higher for fisherfolk than for sex workers (Kissling et al., 2005). In Homa Bay County, there are over 15,000 children (aged 14 and below) in need of ART; concern for continued care and treatment, with decrease in non-adherence, will presumptively reduce incidences and prevalence into their adulthood (National AIDS Control Council of Kenya, 2014).

Villages and towns in the islands of Lake Victoria (Kenya), are dominated by hotels, bars, and tailoring shops, fueled by money from daily sales of fish, and residents seemed to encapsulate a phrase describing Luo's desire to enjoy their life; 'giheroraha,' luo for 'they love pleasure' (Okoth-Okombo, 1999). Due to casual sexual relations in such environment, and as explained by the social epidemiology concept (Berkman and Kawachi, 2000) Freund \&McGuire, 1999, this relates to the early burden of the HIV/AIDS epidemic in SSA. Fishing communities in Uganda (Rakai district), Tanzania (Mwanza and Bukoba provinces) and Kenya (formerly Nyanza province) where the initial cases of HIV/AIDS were recorded in the early 1980s (Barnett and Whiteside, 2002).

Despite effort to fight HIV/AIDS in Lake Victoria regions, both biomedical and social-cultural interventions like voluntary HIV counseling and testing (VCT), prevention of mother-to-child transmission (PMTCT), voluntary medical male circumcision (VMMC), and HIV Exposed Infant (HEI) intervention, Key Populations programming (KP), Pre-and Post-Exposure Prophylaxis (PEP and PrEP), and stopping levirate culture, all exclude direct involvement and engagement of teenage population. A non-teenage focus intervention perhaps is a driver of adultbased HIV/AIDS information dissemination strategies in Kenya.

Exclusion of non-teenage focus intervention present teenagers living with HIV from island communities of Lake Victoria, with single option to attempt to visit health facilities for medical information and services (International Planned Parenthood Federation [IPPF], 2010). However, lack of confidentiality, fear of mistreatment, inconvenient hours and locations of facilities, high costs of services, limited knowledge of available services, lack of privacy and confidentiality, coupled with negative beliefs and attitudes by health care workers, are major barriers for teenagers to seek information (IPPF, 2010) at the health facility. Teenagers also shy away from service offered based on marital status; like couple counseling during pregnancy.

In response to poor health indices catalyzed by low provision of health care services (KAIS, 2014) and low investment in healthcare infrastructure, it is presumed that mHealth ability to cross borders will bridge the gap in the islands. From 2012, teenagers living with HIV/AIDS from island communities of Lake Victoria Kenya have been exposed to various mHealth projects: K-MET's SRHR information ( $e$ and $m$ platforms) and health insurance mTIBA, ADS Nyanza Youth ASK SMS Project; SRHR Alliance GUSO Project; Marie Stopes Kenya M4RH Project, JHPIEGO's TUPANGE Family Planning Project, among others, with continued funding to end by the year 2020. It is with this background that this study.

Important for this study will be to understand mHealth by characterizing teenagers living with HIV from island communities of Lake Victoria and to what extent its (access) effects treatment. Establishing technology obsolescence, while exploring community-based health support systems that possibly facilitate suitable utilization of mHealth by teenagers living with HIV from the island communities of Lake Victoria. Using Probit model, this study wishes to measure utilization of teenager on mHealth against access with interest in the number of: referrals made, ART initiated, and treatment adherents.

\section{Statement of the Problem}

The emergence of mHealth as an alternative access point for care and treatment is lauded by development agencies as ingenious innovation for bridging health care access for teenagers living with HIV/AIDS among detached communities like the islands of Lake Victoria. It is also presumed that mHealth transcends beyond teenagers' concerns with location and unfriendly hours of operation of health facilities. mHealth is alleged to increase privacy and confidentiality, reduce cost of service delivery, and loops over retrogressive cultural beliefs and attitudes exhibited by health care providers and caregivers, consequently increasing access to health information, care and treatment. With increased access to mobile phones, it is presumed that mHealth can easily reach teenagers; a population missed out on national HIV/AIDS interventions. However, despite the growth in mHealth interventions and donor agencies lining up to support its scaling up, enrollment and adherence to treatment by teenagers living with HIV/AIDS in Kenya remains a challenge; a worrisome trend as HIV epidemic in subsequent years will be largely determined by the success made in slowing the spread among teenagers. Information on characterization of mHealth utilization, knowledge management of information, technological obsolescence, and mHealth operationalization in community-based health support is critical for making informed decisions on programing for teenagers on mHealth and living with HIV. Consequently, this called for studies to examine health-information and care and treatment seeking behaviors among teenagers living with HIV and AIDS on mHealth. This study, therefore, 
sought to determine the effect of mHealth utilization on access to treatment by teenagers living with HIV/AIDS in island communities of Lake Victoria.

\section{Research Objectives}

The study was guided by the following research objectives:

i. Determine technology obsolescence on the utilization of mHealth information by teenagers living with HIV from the island communities of Lake Victoria and its effect on treatment access, and

ii. Explore community-based health support systems that facilitate suitable utilization of mHealth by teenagers living with HIV from the island communities of Lake Victoria and its effect on treatment access.

\section{Theoretical Review}

This study was anchored on Health Belief Model and Diffusion Innovation Theory.The Health Belief Model (HBM) explains and predicts health-related behaviors, particularly regarding the uptake of health services (Janz and Marshall, 1984). HBM suggests that people's beliefs about health problems, perceived benefits of and barriers to action and self-efficacy explain engagement (or lack of engagement) in health-promoting behavior (Janz and Marshall, 1984). It opines that a stimulus, or cue to action, must also be present to trigger the health-promoting behavior (Janz and Marshall, 1984). In operationalizing the theory, an attempt to establish characterization of mHealth access of teenagers living with HIV from island communities of Lake Victoria followed a cascade of (i) perceived threat (ii) perceived behavior, and (iii) modifiers such as variables, cues to action, and self-efficacy, and probes into demographics, personality, social class, and peer and reference group pressure, costs, painful, inconvenient, and unpleasant, as an angle of finding out if teenagers believe that the benefits by far outweigh the consequences of continuing the old behavior (Center for Disease Control and Prevention, 2004). The above set provided explanations, why teenagers living with HIV use mobile phones, frequency of use, length of engagement, social media sites known and accessed, and the global connections they have, and primary reason for using the favorite mHealth network. This study took cognizant of the fact that theoretical constructs that constitute the HBM are broadly defined, as interpersonal influences are also particularly difficult to measure as cues (Lupton, 2012). Furthermore, the HBM does not specify how constructs of the model interact with one another (Glanz et al., 2008). Therefore, different operationalizations of the theoretical constructs may not be strictly comparable across studies (Nancy and Marshall, 1984).

Diffusion of innovations explains how, why, and at what rate new ideas and technology spread (Rogers, 2003). Propounded in Everett Rogers's 1962 'Diffusion of Innovations' book, the theory, narrates the process by which an innovation is communicated over time among the participants in a social system, as influenced by the innovation itself, communication channels, time, and a social system. With focused on adoption of technology, obsolescence of desirability or stylistic obsolescence occurs when designers change the styling of products, so customers will increase frequency in purchase, due to the decrease in the perceived desirability of unfashionable items (My Money Bag, 2009), thus leading to continuation or discontinuation (through replacement or disenchantment). This study considered mHealth content (as health information) and mobile phones (as the medium), and if aesthetic is valued rather as opposed to functional reasons. This study presumed that teenagers desire to engage with more fashionable mHealth content through desirable mobile phones. Articles published on Diffusion of Innovations approach created a systematic theory which have not contributed much changes to the evolution of the theory (Greenhalgh et al., 2005); a gap for criticism. This study also acknowledged that diffusion is difficult to quantify because humans and human networks are complex, thus, not possible to measure what exactly causes continuation or discontinuation (Katz et al., 1963).

\section{Conceptual Model and Hypothesis}

The proposed conceptual framework encompassedtechnology obsolescence and sustainability through Community-based health systems (as independent variables) which affect mHealth utilization among teenagers living with HIV (the dependent variable). This is illustrated below;

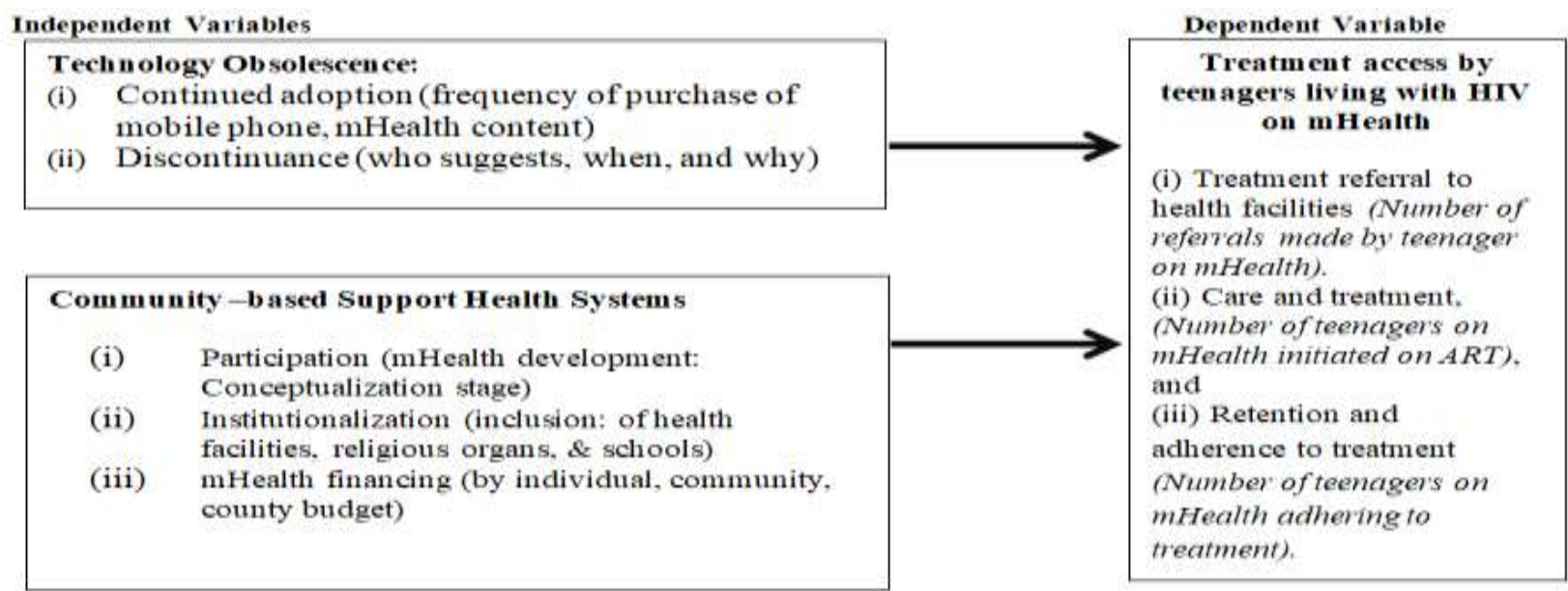




\section{Empirical Review}

Bernard London's pamphlet of 1932, 'Ending the Depression Through Planned Obsolescence,' would have the government impose a legal obsolescence on consumer articles, to stimulate and perpetuate consumption (LeBlanc et al., 2013). Through global value chains, there has been growth in interconnectedness as Multinational Enterprises (MNEs) play an increasingly larger role in the internationalization of business. In response, governments have cut Corporate Income Tax rates or introduced new incentives for research and development to compete in this changing geopolitical landscape (LeBlanc et al., 2013).Obsolescence affects innovation as it is highly pegged to adaptation or discontinuation of products and services in the market; teenagers will equally be aligned to the same cascade, that is, early adopters, early majority, late majority, and laggards, as mobile phones infiltrate the markets in SSA (Lamb et al., 2009).

Today, obsolescence affects diffusion of innovation as it subjected to lifespan-limited design, where all consumer products have an expected average lifetime permeating all stages of development (LeBlanc et al., 2013). Innovation is equally affected by style obsolescence where manufacturers will release slightly updated products at regular intervals and emphasize their value as status symbols (LeBlanc et al., 2013). In developed countries, where many industries already face a saturated market, this technique is often necessary for producers to maintain their revenue (Guiltinan, 2009). Capitalistically, planned obsolescence is advantageous as it stimulates demand by encouraging purchasers by putting them under pressure to buy sooner if they still want a functioning product (Guiltinan, 2009).

Africa's population aged 16-34 accounting for 65 percent of the entire continent's billion-dollar consumer spending; this is the fastest growing continent with smart-phone use, advertisers are obsessing on how best to reach them (Mail \& Guardian Africa Business Magazine, 2015). With arguably the strongest and most passionate musical culture on the planet, by 2020 the teenage and youthful population will dominate Africa's $\$ 1.3$ trillion consumer spending. For such profits to be realized, the continued change in mobile phones physical outlook, their software, and supporting social media platforms becomes the playing ground for continued appreciation of emerging mobile content that attracts the young people (LeBlanc et al., 2013). In addition to adverts, gamification has gained popularity in the world of marketing and customer loyalty (Gagnon et al., 2016).

Evidently, beside the mHealth market offering the desired possibilities of: data collection (where mobile devices replace and/or complement traditional paper-based tools); and behavior change, (where mobile devices are used to disseminate key messages and good practices among communities in Africa), there are direct contribution to the global mobile phone market revenue, which is predicted to grow to from 4.5 to 24 billion USD from 2013 to 2018 respectively (GSMA \& PwC, 2012). Discourse on sustainability of community-based HIV/AIDS projects in SSA, is because the epidemic has affected the family as a functioning system, threatened its supportive capacity, and redefined the manner of coping and adapting mechanisms (Safdari et al., 2018). With an estimated 2.7 million people in SSA becoming newly infected, it is projected that close to 25 million children will become orphans by the 2010 Heymann et al. (2007); this calls for a response to factors which might challenge viability and relevance of mHealth projects targeting teenagers living with HIV/AIDS.

In low-income countries, negative attitude of society exhibited by discrimination and stigmatization (Bonuck, 1993), affects not only physical health but mental and social conditions of persons living with HIV/AIDS (Peltzer and Ramlagan, 2011), making them experience social drift (Kadushin, 1996) with loss of family as major sources of support (Hall, 1999). Coping with HIV infection requires community support (Florence et al., 1994), with disclosure of status to support groups results in greater social and emotional support for PLWHA (Bor et al., 1993). It is therefore suggested that a process by which citizens act in response to public concerns, voice their opinions about decisions that affect them, and take responsibility for changes to their community should be initiated (Jowett and Armitage, 1988); hence defining Participatory Approach (PA).Despite the rapid uptake of PA approaches in the $21^{\text {st }}$ century, the central danger lies in the fact that organizations are simply using the name and techniques of PA without any thought or uptake of the philosophy of PA (Chambers, 1997). It should be noted that PA is about needs identification and problem resolution at a fundamental level, that is, if no action is taken on the communities' recommendations, the groups involved become demoralized and demotivated (Chambers, 1997). However, there are disadvantaged minorities (which may include teenagers) whose participation in development activities may be strongly resisted by gate keepers and dominant community-based groups (Nöstlinger et al., 2015).

There is also the risk that a participatory methodology is providing a rational, systematic and coherent framework from which to work from Nöstlinger et al. (2015). Bad experiences with (non-) supporting agencies may have robbed them of any hope for improvement, depleted their self-confidence and increased their distrust of outsiders - resulting in a 'culture of silence' (Nöstlinger et al., 2015). Nevertheless, PA uptake by organizations is encouraging (Safdari et al., 2018), as lack of appropriate participatory approaches limit uptake and sustainability of development initiatives has recently been linked to over-reliance on 'expert' knowledge and inadequate appreciation of local development priorities (Tufte, 2009).

\section{Methodology}

Cross-sectional study design was used to demonstrate relationships (Kothari, 2004) and describes the effect of mHealth utilization on access to treatment by teenagers living with HIV/AIDS in island communities of Lake Victoria. Applying both qualitative and quantitative research techniques (Shields and Nandhini, 2013), the survey method related mHealth access to: number of referrals, number of teenagers initiated on ART, and number of teenagers adhering to treatment. The study employed the probit model for the anticipated binary response in 
utilization of mHealth and access to treatment. The study was carried out in islands of Lake Victoria that is, Ringiti, Remba, Rusinga, Mfangano and Mageta, which lie in the eastern part of Lake Victoria (in Kenya). The choice of the study area was based on (i) poor health indices affecting the teenagers in the regions (i.e., HIV/AIDS, Malnutrition, Unwanted and Unplanned Pregnancies, Termination of Pregnancies, Sexually Transmitted Infections) and (ii) low provision of health care services (KAIS, 2014) due to the detachment from mainland and limited investment in healthcare infrastructure.

The population study was teenagers (13 to 19 years) who have: (i) tested HIV positive, (ii) are in registered support groups facilitated by government hospitals, and (iii) have personal mobile phones or can access one at household level.Data on number of teenagers living with HIV/AIDS among island communities of Lake Victoria is not conclusive. Despite daily initiation of new patients (teenagers), it is still difficult to tell the exact number as decision to take a HIV test and later access treatment at designated points is entirely an individual's effort. Many a times, deaths of teenagers caused by co-infections from HIV/AIDS go undocumented. Consequently, a comprehensive list of teenagers on treatment cannot be generated. This study focused on teenagers living with HIV/AIDS and is on mHealth; and a control of the same who are not on mHealth. As of July 2017, a total of 409 were registered (using unique identification codes) at various comprehensive care clinics across the five islands; this is the target population size.The sample size for this study was estimated using the following statistical sample determination formulae below by William G. Cochran:

...where:

$$
\mathrm{n}=\frac{\mathrm{X}^{2} * \mathrm{~N} * \mathrm{P} *(1-\mathrm{P})}{\left(\mathrm{ME}^{2} *(\mathrm{~N}-1)\right)+\left(\mathrm{X}^{2} * \mathrm{P} *(1-\mathrm{P})\right)}
$$

$\mathrm{n}=$ sample size

$\mathrm{X}^{2}=$ Chi-square for the specified confidence level at 1 degree of freedom

$\mathrm{N}=$ population size

$\mathrm{P}=$ Population proportion $(.50)$

$\mathrm{ME}=$ desired margin of error (expressed as a proportion).

...therefore:

Nis approximately 409 (from health facility records - as of July 2017)

$\mathbf{P}=0.5 \mathbf{M E}=5 \%(0.05) \mathbf{X}^{2}=3$

$n=\frac{3 * 409 * 0.5(1-0.5)}{\left(\mathrm{ME}^{2} *(409-1)\right)+(3 * 0.5 *(1-0.5))}=n=173.30508475$

$n=173.30508475$ as sample of teenagers living with HIV (this is approximately 173).

Due to the nature of the study, that is, its sensitivity and inclusion criterion, the study worked with teenage support groups. At level one, through government local health facilities, willing Health Workers engaged teenagers living with HIV at the comprehensive clinics were identified and requested to participate in the study as guides and link creators. In turn, the health workers introduced the research and researcher to existing support groups, where they were engaged as key informants, interviewees for structured questionnaire and members of a focus group discussion. At level two, stratified random sampling was applied to ensure each stratum was taken in a number proportional to the stratum's size as compared to the population. A control group was introduced to measure any differences in access to treatment between users and non-users of mHealth. At level three, members that formed a control group were identified to help eliminated the influence of some extraneous factor (Campbell and Stanley, 1963); 30 percent of the sample size will apply as illustrated in Table 1.

Table-1. Study Sample Size

\begin{tabular}{l|l|l|l|l}
\hline Islands & $\begin{array}{l}\text { Approximated population of } \\
\text { teenagers living with HIV on } \\
\text { care and treatment }(\boldsymbol{N = 4 0 9 )}\end{array}$ & $\begin{array}{l}\text { Proportion to } \\
\text { total population } \\
(\boldsymbol{\%})\end{array}$ & $\begin{array}{l}\text { Sample size }(\boldsymbol{n} \\
\boldsymbol{=} \mathbf{1 7 3})\end{array}$ & $\begin{array}{l}\text { Control Group } \\
\text { sample }(\mathbf{3 0 \%} \text { of } \boldsymbol{n})\end{array}$ \\
\hline Ringiti & 39 & 9.535 & 16.496 & 4.9488 \\
\hline Rusinga & 133 & 32.518 & 56.256 & 16.8768 \\
\hline Mfangano & 114 & 27.873 & 48.22 & 14.4660 \\
\hline Remba & 22 & 5.379 & 9.306 & 2.7918 \\
\hline Mageta & 101 & 24.694 & 42.721 & 12.8163 \\
\hline Total & $\mathbf{4 0 9}$ & $\mathbf{1 0 0}$ & $\mathbf{1 7 2 . 9 9 8}$ & $\mathbf{5 1 . 8 9 9 7}$ \\
\hline
\end{tabular}

\section{Results and Discussion}

\subsection{Response Rate}

Questionnaires were issued to a sample of 173 respondents domiciled in Ringiti, Remba, Mfangano, Rusinga and Mageta all lying in the eastern part of Lake Victoria-Kenya. A total of 138 questionnaires were received back, giving a response rate of $80.2 \%$ which the study considered adequate for the purposes of analysis. According to Ørngreen and Levinsen (2017), a response rate of 50\% is adequate for analysis and reporting; a rate of $60 \%$ is good and a response rate of $70 \%$ and over is excellent. Based on the assertion, the response rate was excellent and, therefore, representative and satisfactory to make conclusions for the study. This collaborates with the assertion by Gog (2015) that a response rate of $50 \%$ is adequate, while a response rate greater than $70 \%$ is very good. 


\subsection{Technology Obsolescence}

\subsubsection{Descriptive Analysis for Construct Technology Obsolescence}

In this section the study intended to establish the mobile phone changed, reasons for changing and information packaged aligns to teenager's phone usage to access treatment. The study sough to establish the number of times the teenagers had changed their phone numbers in the past 5 years covering the study period that is from the year 2013 up to 2017. From Table 2, the result indicated that 34\% had changed their mobile phones once, $25 \%$ had changed their mobile phones twice, $19 \%$ had changed their phones three times while those who had changed their phones four and five times were $9 \%$ a piece. Those who had changed 6 times were $2 \%$ while those who had never changed was $1 \%$. The study results imply that teenagers do change their phones to access treatment through $\mathrm{m}$-health in the Islands of Victoria.

In addition, the study sought to investigate reasons for changing the mobile phones for the study period. It was established that that most of the teenagers $(46 \%)$ did change their phones because the phones had problems with memory, $33 \%$ posited due to phones had problems with batteries, $26 \%$ cited that they had to also upgrade because of what their friends had, $18 \%$ changed because their phone models were wiped off the market and $15 \%$ did change their phones because some apps could not be downloaded. This imply that teenagers changed mobile phones due to a variety of reasons so that they could access treatment through m-Health in the Island communities of Lake Victoria.

Further, pertaining to whether m-Health information was packaged in line with how the teenagers communicate to their peers, majority at $47.1 \%$ were not sure, $45.7 \%$ observed that it did not while only $7.2 \%$ agreed it was packaged in line with the phones usage. They also indicated that, wished that the language used could be changed (49\%), 32\% wished that the time of sending the messages could be changed while $57 \%$ felt that the text format could be changed.

Table-2. Mobile phone changed, reasons for changing and information packaged aligns toTeenager's phone Usage

\begin{tabular}{|c|c|c|}
\hline \multirow[t]{2}{*}{ Category } & \multicolumn{2}{|l|}{ Case } \\
\hline & $\mathbf{n}=\mathbf{1 3 8}$ & $\%$ \\
\hline \multicolumn{3}{|l|}{ Number of times a mobile phone has been changed } \\
\hline Once & & 34 \\
\hline Twice & & 25 \\
\hline Three times & & 19 \\
\hline Four times & & 9 \\
\hline Five times & & 9 \\
\hline Six times & & 1 \\
\hline Never & & 1 \\
\hline \multicolumn{3}{|l|}{ Reason for changing mobile phone } \\
\hline My model was wiped off the market & & 18 \\
\hline My friends bought new ones so copied them & & 26 \\
\hline My phone had problems with memory & & 46 \\
\hline My phone had problems with battery power & & 33 \\
\hline Some Apps cannot be downloaded in my old phone & & 15 \\
\hline \multicolumn{3}{|l|}{ Information packaged in line with teenager's phone usage } \\
\hline Language used & & 49 \\
\hline Time of sending messages & & 32 \\
\hline Format text & & 57 \\
\hline
\end{tabular}

\subsection{Correlation Analysis}

The study sought to establish the relationship between technology obsolescence and access to treatment by teenagers living with the HIV. A Pearson Correlation was performed, and the result of the Pearson correlation test as presented in Table 3 show a correlation $(\mathrm{r}(138)=0.346 ; \mathrm{p}<0.05)$ between the technology obsolescence and access to treatment by teenagers living with the HIV. This implies that the technology obsolescence is positively correlated to the access to treatment by teenagers living with the HIV. In addition, the correlation between these two variables was positive and significant, that is $\mathrm{p}<0.5$ implying a linear relationship between the technology obsolescence and access to treatment by teenagers living with the HIV.

Table-3. Correlation Analysis of Technology Obsolescence

\begin{tabular}{l|l|l}
\hline \multicolumn{2}{|c|}{} & Access to Treatment \\
\hline \multirow{3}{*}{ Access to Treatment } & $\mathrm{R}$ & 1.000 \\
\cline { 2 - 3 } & Sig. (2-tailed) & \\
\cline { 2 - 3 } Technology Obsolescence & $\mathrm{N}$ & \\
\cline { 2 - 3 } & $\mathrm{R}$ & .346 \\
\cline { 2 - 3 } & Sig. (2-tailed) & .000 \\
\cline { 2 - 3 } & $\mathrm{N}$ & 138 \\
\hline
\end{tabular}




\subsection{Regression Analysis}

This study applied a regression model to identify the effect of technology obsolescence and impact on access to treatment by teenagers living with HIV. Regression analysis was conducted to determine the proportion of access to treatment (dependent variable) which could be predicted by technology obsolescence(independent variable). It was hypothesized that:

$\mathrm{H}_{\mathrm{a} 2}$ : There is significant relationship between technology obsolescenceand treatment access by teenagers living with HIV from island communities of Lake Victoria.

To test this hypothesis, the model $\mathrm{Y}=\beta_{0}+\beta_{1} \mathrm{X}_{1}+\varepsilon$ was fitted. Where $\mathrm{Y}$ is treatment access by teenagers living with HIV from island communities of Lake Victoria $\mathrm{X}_{1}$ is technology obsolescence

Regression model summary results in Table 4indicate the goodness of fit for the regression between technology obsolescence and treatment access by teenagers living with HIV from island communities of Lake Victoriawas satisfactory in the linear regression model. An R squared of 0.362 indicates that $36.20 \%$ of the variances in treatment access by teenagers living with HIV from island communities of Lake Victoria are explained by the variances in technology obsolescence. However, the model failed to explain $63.80 \%$ of the variation in treatment access by teenagers living with HIV from island communities of Lake Victoria. This means that there are other factors associated with treatment access by teenagers living with HIV from island communities of Lake Victoriawhich were not explained by the model. The correlation coefficient of 0.476 indicates technology obsolescencehas a positive correlation with treatment access by teenagers living with HIV from island communities of Lake Victoria.

Table-4. Model Summary (Technology Obsolescence and Access to Treatment)

\begin{tabular}{l|l|l|l|l}
\hline Model & $\mathrm{R}$ & $\mathrm{R}$ Square & Adjusted R Square & Std. Error of the Estimate \\
\hline 1 & $.476 \mathrm{a}$ & .362 & .252 & 1.342 \\
\hline \multicolumn{2}{l}{ a. Predictors: (Constant), Knowledge Management }
\end{tabular}

The ANOVA results in Table 5 shows that $(\mathrm{F}(1,136)=77.178, \mathrm{p}<0.05)$. This shows that the overall model significant. The findings imply that technology obsolescencewas statistically significant in explaining treatment access by teenagers living with HIV from island communities of Lake Victoria. Therefore, at $\mathrm{p}<0.05$ level of significance, null hypothesis is not supported thus rejected and the alternative hypothesis $\left(\mathrm{H}_{\mathrm{a} 1}\right)$ which states that "There is a significant relationship between technology and treatment access by teenagers living with HIV from island communities of Lake Victoria" is accepted implying that technology has a significant influence on treatment access by teenagers living with HIV from island communities of Lake Victoria.

Table-5. ANOVA Statistics (Technology Obsolescence and Treatment Access.)

\begin{tabular}{l|l|l|l|l|l|l}
\hline \multicolumn{2}{l|}{ Model } & Sum of Squares & Df & Mean Square & F & Sig. \\
\hline \multirow{4}{*}{1} & Regression & 131.435 & 1 & 131.435 & 77.178 & $.000^{\mathrm{b}}$ \\
\cline { 2 - 8 } & Residual & 231.645 & 136 & 1.703 & & \\
\cline { 2 - 7 } & Total & 363.080 & 137 & & & \\
\hline \multicolumn{2}{l}{ a. Dependent Variable: Access to Treatment }
\end{tabular}

b. Predictors: (Constant), Technology Obsolescence

Regression of coefficients results in Table 6 shows that there is a positive and significant relationship between technology obsolescence and treatment access by teenagers living with HIV from island communities of Lake Victoria as supported by a $\mathrm{p}<0.05$ and a beta coefficient of 0.388 . This implies that a unit increase in technology obsolescence would increase the treatment access by teenagers living with HIV from island communities of Lake Victoria by 0.469 units. This was supported by the $t$ values whereby $t$ cal $=2.896>t$ critical $=1.96$ at a 95 percent confidence level which depicts that we reject the null and accept the alternative hypothesis. Further, this confirms the positive effect of technology obsolescence on treatment access by teenagers living with HIV from island communities of Lake Victoria. The fitted equation is as shown below: $\mathrm{Y}=2.896+0.469 \mathrm{X}_{1}$ that is treatment access by teenagers living with HIV from island communities of Lake Victoria $=2.896+0.469$ Technology Obsolescence

Table-6. Regression Coefficients (Technology Obsolescenceand Treatment Access)

\begin{tabular}{|c|c|c|c|c|c|c|}
\hline & & \multicolumn{2}{|c|}{$\begin{array}{l}\text { Unstandardized } \\
\text { Coefficients }\end{array}$} & \multirow{2}{*}{$\begin{array}{l}\text { Standardized Coefficients } \\
\text { Beta }\end{array}$} & \multirow[b]{2}{*}{$\mathbf{T}$} & \multirow[b]{2}{*}{ Sig. } \\
\hline \multicolumn{2}{|c|}{ Model } & B & Std. Error & & & \\
\hline \multirow[t]{2}{*}{1} & (Constant) & 2.896 & .543 & & 5.320 & .000 \\
\hline & $\begin{array}{l}\text { Technology } \\
\text { Obsolescence }\end{array}$ & .469 & .171 & .362 & 2.743 & .000 \\
\hline
\end{tabular}

a. Dependent Variable: Treatment access by teenagers living with HIV from island communities of Lake Victoria. 


\subsection{Community Based Health Systems}

\subsubsection{Descriptive Analysis for Community Based Health Systems}

Regarding the above objective, there was the need to establish whether the teenagers had been involved in message development, social marketing and community entry of the mHealth Apps they have engaged with. The results in Table 7 showed that $2.1 \%$ of the teenagers who have been involved in message development, were involved in selecting mHealth HIV message package, $6.5 \%$ were involved in developing prototype of mHealth HIV message, $2.9 \%$ who were involved in pretesting of mHealth HIV message prototype as well as process monitoring of utilization of mHealth HIV message package and $84.80 \%$ were not involved at any stage of message development for mHealth. The study results indicate that the teenagers had been involved in message development, in selecting mHealth HIV message package, developing prototype of mHealth HIV message as well as process monitoring of utilization of mHealth HIV message package.

Pertaining to whether the respondents have been involved in social marketing activities of mHealth Apps, $16 \%$ of the teenagers posited that they identified the influencers, $49 \%$ respondents had been involved but 88 respondents had not been involved. From those who had participated in social marketing activities, 16 respondents were involved in the identification of influencers, 33 were involved in the identification of partners and $51 \%$ were not involved in social marketing activities. The study findings imply that involvement in social marketing of mHealth Apps was not for identification of the influencers or partners.

In addition, the study sought to examine the teenagers' level of community entry and the study results indicated that $2.9 \%$ identified objectives and evaluation criteria for mHealth indicators; $30.4 \%$ stated that they conducted livelihoods analysis on teenagers living with HIV, education of teenagers on m-Health access and utilization, 9.4\% of the teenagers indicated that they mapped community linkages for teenagers on mHealth and $52.5 \%$ indicated that they did not involve in community entry. This can be deduced that teenagers' level of community entry was low in the communities in Islands of Victoria.The study went further to find out who could sustainably fund mHealth Apps for the use of teenagers to access treatment. The study found out that majority of the teenagers indicated that NGOs played a big role to fund mHealth Apps (58.0\%), the CBOs also funded (35.5\%), 3.6\% of the respondents indicated that the church could fund m-Health Apps and existing health facility also funded the mHealth Apps (3.6\%). The study results indicated that NGOs played a big role to fund mHealth Apps for the teenagers to access treatment for the communities living with HIV in Islands of Victoria.

The study also sought to examine on the teenagers incentivization to use mHealth Apps. The study findings indicated that $18.10 \%$ of the respondents indicated provision of airtime, $20.30 \%$ of the respondents stated awarding of points of accessing the Apps, $10.10 \%$ of the respondents indicated purchase of mobile phones for teenagers, $2.90 \%$ indicated facilitation of exchange tours and $48.60 \%$ of the respondents stated none of the above. This indicated that awarding of points of accessing the Apps, purchase of mobile phones for teenagers and indicated facilitation of exchange tours could not enhance teenager's incentivization to use mHealth Apps in communities in Islands of Lake Victoria.

Table-7. Teenager's involvement in message development, social marketing and community entry

\begin{tabular}{|c|c|c|}
\hline \multirow[t]{2}{*}{ Category } & \multicolumn{2}{|l|}{ Case } \\
\hline & $\mathrm{n}=\mathbf{1 3 8}$ & $\%$ \\
\hline \multicolumn{3}{|l|}{ Involvement in message development of mHealth Apps } \\
\hline Selecting mHealth HIV message package & 4 & 2.9 \\
\hline Developing prototype of mHealth HIV message & 9 & 6.5 \\
\hline Pretesting of mHealth HIV message prototype & 4 & 2.9 \\
\hline Process monitoring of utilization of mHealth HIV message package & 4 & 2.9 \\
\hline Not involved at any stage & 117 & 84.8 \\
\hline \multicolumn{3}{|l|}{ Involvement in social marketing of mHealth Apps } \\
\hline Identification of influencers & 16 & 22.1 \\
\hline Identification of partners & 33 & 45.5 \\
\hline Not involved in social marketing activities & 51 & 70.4 \\
\hline \multicolumn{3}{|l|}{ Involvement in community entry for mHealth Apps } \\
\hline Identify objectives and evaluation criteria for mHealth indicators & 4 & 2.9 \\
\hline Conduct livelihoods analysis on teenagers living with HIV & 42 & 30.4 \\
\hline Education of teenagers on mHealth access and utilization & 13 & 9.4 \\
\hline Mapping of community linkages for teenagers on mHealth & 7 & 5.1 \\
\hline Not involved in community entry & 72 & 52.2 \\
\hline \multicolumn{3}{|l|}{ Who can sustainably fund mHealth Apps? } \\
\hline The church & 5 & 3.6 \\
\hline Health facility & 4 & 2.9 \\
\hline NGOs & 80 & 58.0 \\
\hline CBOs & 49 & 35.5 \\
\hline
\end{tabular}




\begin{tabular}{|l|l|l}
\hline Teenagers incentivization to use mHealth Apps & & \\
\hline Provision of airtime & 25 & 18.1 \\
\hline Awarding of points of accessing the Apps & 28 & 20.3 \\
\hline Purchase of mobile phones for teenagers & 14 & 10.1 \\
\hline Facilitation of exchange tours & 4 & 2.9 \\
\hline None & 67 & 48.6 \\
\hline
\end{tabular}

The study investigated on the usage of Apps that prompts referral for medical attention by the teenagers in the study area. The study findings in Table 8 indicated that $32.6 \%$ of the respondents stated drug picking, $30.40 \%$ indicated drug taking, $37.0 \%$ of the respondents indicated did not use a phone to prompt appointments. On the method for prompt via m-Health, $48.60 \%$ of the respondents indicated mobile phone alarm with dates, $13.0 \%$ got calls from the health facility, $1.40 \%$ Pre-set SMS to send to self and $37.0 \%$ did not use a phone to prompt appointments. The study sought to examine the usage of apps that prompts referral for medical attention, $8.6 \%$ of the respondents indicated the sought counseling on HIV issues, $11.50 \% \%$ of the respondents indicated tested HIV, $5.80 \%$ indicated treatment of opportunistic infections and $74.10 \%$ stated that they did not use an app that prompted referral. The study findings indicated that usage of apps prompted referral for medical attention, counseling on HIV issues, tested HIV, treatment of opportunistic infections and to some extent prompted referrals.

On what facilitated the process of referral most; $85.50 \%$ of the respondents indicated that they did not make referrals using the mHealth App., 7.20\% of the respondents stated services were available in their island, $1.40 \%$ of the respondents stated distance to health facility was not an issue, $4.3 \%$ of the respondents indicated health care workers was receptive and $1.40 \%$ of the respondents indicated an operational teenage friendly center at the facility. The study findings imply that make referrals using the m-Health App, services available in their island, distance to health facility, health care workers and operational teenage friendly center at the facility facilitated the process of referral most in the study area.

On the referral information desired by teenagers to be on m-Health, $85.5 \%$ of the respondents indicated emergency medical attention, $7.2 \%$ of the respondents stated place to seek counseling, $1.4 \%$ of the respondents indicated place to test for HIV, 4.35 of the respondents stated treatment for opportunistic infections and $1.4 \%$ indicated contraceptive information. The study findings indicated that emergency medical attention, place to seek counseling, place to test for HIV, treatment for opportunistic infections and contraceptive information were some of the reasons for referral information desired by teenagers to be on mHealth.

Table-8. Use of mHealth Apps to prompt referral for medical attention

\begin{tabular}{|c|c|c|}
\hline \multirow[t]{2}{*}{ Category } & \multicolumn{2}{|l|}{ Case } \\
\hline & $\mathrm{n}=\mathbf{1 3 8}$ & $\%$ \\
\hline \multicolumn{3}{|l|}{ Prompts via mHealth } \\
\hline Drug picking & 45 & 32.6 \\
\hline Drug taking & 42 & 30.4 \\
\hline Did not use a phone to prompt appointments & 51 & 37.0 \\
\hline \multicolumn{3}{|l|}{ Method for prompt via mHealth } \\
\hline Mobile phone alarm with dates & 67 & 48.6 \\
\hline Get calls from the health facility & 18 & 13.0 \\
\hline Pre-set SMS to send to self & 2 & 1.4 \\
\hline Did not use a phone to prompt appointments & 51 & 37.0 \\
\hline \multicolumn{3}{|l|}{ Use of Apps that prompts referral for medical attention } \\
\hline Seek counseling on HIV issues & 12 & 8.6 \\
\hline Testing of HIV & 16 & 11.5 \\
\hline Treatment of opportunistic infections & 8 & 5.8 \\
\hline Did not use an app that prompts referral & 103 & 74.1 \\
\hline \multicolumn{3}{|l|}{ What facilitated the process of referral most } \\
\hline Did not make referrals using the mHealth App. & 118 & 85.5 \\
\hline Services are available in my island & 10 & 7.2 \\
\hline Distance to health facility is not an issue & 2 & 1.4 \\
\hline Health care workers are receptive & 6 & 4.3 \\
\hline An operational teenage friendly center at the facility & 2 & 1.4 \\
\hline \multicolumn{3}{|l|}{ Referral information desired by teenagers to be on mHealth } \\
\hline Emergency medical attention & & 35 \\
\hline Place to seek counseling & & 24 \\
\hline Place to test for HIV & & 14 \\
\hline Treatment for opportunistic infections & & 64 \\
\hline Contraceptive information & & 1 \\
\hline
\end{tabular}




\subsection{Correlation Analysis}

The study sought to establish the relationship between community-based health systems and access to treatment by teenagers living with the HIV. A Pearson Correlation was performed, and the result of the Pearson correlation test as presented in Table 9 show a correlation $(\mathrm{r}(138)=0.339 ; \mathrm{p}<0.05)$ between the community-based health systems and access to treatment by teenagers living with the HIV. This implies that the community-based health systems is positively correlated to the access to treatment by teenagers living with the HIV. In addition, the correlation between these two variables was positive and significant, that is $\mathrm{p}<0.5$ implying a linear relationship between the communitybased health systems and access to treatment by teenagers living with the HIV.

Table-9. Correlation Analysis of Community Based Health Systems

\begin{tabular}{l|l|l}
\hline \multicolumn{2}{|l}{} & Access to Treatment \\
\hline \multirow{3}{*}{ Access to Treatment } & $\mathrm{R}$ & 1.000 \\
\cline { 2 - 3 } & Sig. (2-tailed) &. \\
\cline { 2 - 3 } & $\mathrm{N}$ & \\
\hline \multirow{2}{*}{$\begin{array}{l}\text { Community Based Health } \\
\text { Systems }\end{array}$} & $\mathrm{R}$ & .339 \\
\cline { 2 - 3 } & Sig. (2-tailed) & .000 \\
\cline { 2 - 3 } & $\mathrm{N}$ & 138 \\
\hline
\end{tabular}

\subsection{Regression Analysis}

This study applied a regression model to identify the effect of community-based health systems and impact on access to treatment by teenagers living with HIV. Regression analysis was conducted to determine the proportion of access to treatment (dependent variable) which could be predicted by community-based health systems (independent variable). It was hypothesized that:

$\mathrm{H}_{\mathrm{a} 2}$ : There is significant relationship between community-based health systems and treatment access by teenagers living with HIV from island communities of Lake Victoria.

To test this hypothesis, the model $Y=\beta_{0}+\beta_{1} X_{2}+\varepsilon$ was fitted. Where $Y$ is treatment access by teenagers living with HIV from island communities of Lake Victoria $\mathrm{X}_{2}$ is community-based health systems

Regression model summary results in Table 10 indicate the goodness of fit for the regression between community-based health systems and treatment access by teenagers living with HIV from island communities of Lake Victoriawas satisfactory in the linear regression model. An R squared of 0.216 indicates that $21.60 \%$ of the variances in treatment access by teenagers living with HIV from island communities of Lake Victoria are explained by the variances in community-based health systems. However, the model failed to explain $78.40 \%$ of the variation in treatment access by teenagers living with HIV from island communities of Lake Victoria. This means that there are other factors associated with treatment access by teenagers living with HIV from island communities of Lake Victoriawhich were not explained by the model. The correlation coefficient of 0.465 indicates community-based health systems has a positive correlation with treatment access by teenagers living with HIV from island communities of Lake Victoria.

Table-10. Model Summary (Community Based Health Systems and Access to Treatment)

\begin{tabular}{l|l|l|l|l}
\hline Model & $\mathrm{R}$ & $\mathrm{R}$ Square & Adjusted R Square & Std. Error of the Estimate \\
\hline 1 & $.465 \mathrm{a}$ & .216 & .207 & 3.9876 \\
\hline \multicolumn{4}{l}{} \\
\multicolumn{2}{l}{ a. Predictors: (Constant), Community Based Health Systems }
\end{tabular}

The ANOVA results in Table 11 shows that $(\mathrm{F}(1,136)=37.470, \mathrm{p}<0.05)$. This shows that the overall model significant. The findings imply that community-based health systems were statistically significant in explaining treatment access by teenagers living with HIV from island communities of Lake Victoria. Therefore, at $\mathrm{p}<0.05$ level of significance, null hypothesis is not supported thus rejected and the alternative hypothesis $\left(\mathrm{H}_{\mathrm{a} 2}\right)$ which states that "There is a significant relationship between community-based health systemsand treatment access by teenagers living with HIV from island communities of Lake Victoria" is accepted implying that community based health systems has a significant influence on treatment access by teenagers living with HIV from island communities of Lake Victoria.

Table-11. ANOVA Statistics (Community Based Health Systems and Treatment Access.)

\begin{tabular}{|c|c|c|c|c|c|c|}
\hline Model & & Sum of Squares & Df & Mean Square & $\mathrm{F}$ & Sig. \\
\hline \multirow{3}{*}{1} & Regression & 78.425 & 1 & 78.425 & 37.470 & $.000^{\mathrm{b}}$ \\
\hline & Residual & 284.655 & 136 & 2.093 & & \\
\hline & Total & 363.080 & 137 & & & \\
\hline
\end{tabular}

Regression of coefficients results in Table 12 shows that there is a positive and significant relationship between community-based health systems and treatment access by teenagers living with HIV from island communities of Lake Victoria as supported by a $\mathrm{p}<0.05$ and a beta coefficient of 0.408 . This implies that a unit increase in community-based health systems would increase the treatment access by teenagers living with HIV from island communities of Lake Victoria by 0.408 units. This was supported by the $t$ values whereby $t$ cal $=2.266>t$ critical $=1.96$ at a 95 
percent confidence level which depicts that we reject the null and accept the alternative hypothesis. Further, this confirms the positive effect of community-based health systems on treatment access by teenagers living with HIV from island communities of Lake Victoria. The fitted equation is as shown below: $\mathrm{Y}=3.908+0.408 \mathrm{X}_{2}$ that is treatment access by teenagers living with HIV from island communities of Lake Victoria $=3.908+0.408$ community-based health systems.

Table-12. Regression Coefficients (Community Based Health Systems and Treatment Access

\begin{tabular}{|c|c|c|c|c|c|c|}
\hline & & \multicolumn{2}{|c|}{ Unstandardized Coefficients } & \multirow{2}{*}{\begin{tabular}{|l|}
$\begin{array}{l}\text { Standardized } \\
\text { Coefficients }\end{array}$ \\
Beta \\
\end{tabular}} & \multirow[b]{2}{*}{$\mathbf{T}$} & \multirow[b]{2}{*}{ Sig. } \\
\hline \multicolumn{2}{|c|}{ Model } & B & Std. Error & & & \\
\hline \multirow[t]{2}{*}{$\overline{1}$} & (Constant) & 3.908 & .909 & & 4.299 & .000 \\
\hline & $\begin{array}{l}\text { Community based } \\
\text { health systems }\end{array}$ & .408 & .180 & .216 & 2.266 & .000 \\
\hline
\end{tabular}

\section{Conclusion}

The study sought to determine technology obsolescence on the utilization of m-Health information by teenagers living with HIV from the island communities of Lake Victoria and its effect on treatment access. From the inferential analysis, the study concludes that technology obsolescence significantly affected access to treatment by teenagers living with HIV/AIDS in island communities of Lake Victoria. The study results are in tandem with the findings by Gagnon et al. (2016) found out that beside the m-Health market offering the desired possibilities of: data collection (where mobile devices replace and/or complement traditional paper-based tools); and behavior change, (where mobile devices are used to disseminate key messages and good practices among communities in Africa), there are direct contribution to the global access to medical support.

The study sought to explore community-based health support systems that facilitate suitable utilization of $\mathrm{m}$ Health by teenagers living with HIV from the island communities of Lake Victoria and its effect on treatment access. From the inferential analysis, the study concludes that community-based health support systems positively and significantly affected access to treatment by teenagers living with HIV/AIDS in island communities of Lake Victoria. The study results are in line with the findings by Safdari et al. (2018) found out that discourse on sustainability of community-based HIV/AIDS projects in SSA, is because the epidemic has affected the family as a functioning system, threatened its supportive capacity, and redefined the manner of coping and adapting mechanisms. Coping with HIV infection requires community support with disclosure of status to support groups results in greater social and emotional support. It is therefore suggested that a process by which citizens act in response to public concerns, voice their opinions about decisions that affect them, and take responsibility for changes to their community should be initiated, hence defining participatory approach.

\section{Recommendation}

The study found that the mHealth dimensions had a significant positive effect on access to treatment by teenagers living with HIV/AIDS in island communities of Lake Victoria. The policy implications will be highly relevant regarding mHealth utilization which require to be implemented through multi-dimensional approach may render improved access to treatment by teenagers living with HIV/AIDS than the single-dimensional approach in island communities of Lake Victoria. This has important implications for the design of mHealth utilization and implementation strategies to policymakers. Moreover, the strength of the influence of technology obsolescence and community support systems are highly relevant for policymakers in developing countries in the context of on-going health sector management and institutional reforms. If mHealth process can render larger positive effects on access to treatment by teenagers living with HIV/AIDS, designing adequate m-health utilization and frameworks in the Islands of Lake Victoria could help significantly in increasing the quality of life of teenagers through better access to treatment services. The study thus assists policymakers in coming up with policies geared towards improving access to treatment by teenagers living with HIV/AIDS in island communities of Lake Victoria.

\section{References}

Banjanovic, A. (2009). Special Report: Towards universal global mobile phone coverage. Euromonitor International: $247-57$.

Barnett, T. and Whiteside, A. (2002). AIDS in the 21st century disease and globalization. Routledge: London. http://www.ncbi.nlm.nih.gov/pmc/articles/PMC3387685/\#R3

Berkman, F. and Kawachi, I. (2000). A historical framework for social epidemiology. In: Berkman Lisa F, Kawachi Ichiro., editors. Social epidemiology. Oxford University Press: New York. 3-12. http://www.ncbi.nlm.nih.gov/pmc/articles/PMC3387685/\#R5

Bonuck, K. (1993). AIDS and families: cultural, psychosocial, and functional impacts. Social Work in Health Care, 18(2): 75-89.

Bor, R., Miller, R. and Goldman, E. (1993). HIV/AIDS and the Family: A review of research in the first decade. Journal of Family Therapy, 15(2): 187-204.

Campbell, D. and Stanley, C. (1963). Experimental and quasi-experimental designs for research. Chicago: Rand McNally. https://journals.uair.arizona.edu/index.php/jmmss/article/viewFile/18302/18037 
Chambers, R. (1997). Whose reality counts: Putting the first last. London: Intermediate Technology Publications.

Chipchase, S. Y., Treece, K. A., Pound, N., Game, F. L. and Jeffcoate, W. J. (2005). Heel ulcers don't heal in diabetes. Or do they? Diabetic Medicine, 22(9): 1258-62.

Florence, M., Lutzen, K. and Alexius, B. (1994). Adaptation of heterosexual infected HIV positive women: A swedish pilot study. Health for Women International, 15(4): 265-73.

Gagnon, M. P., Ngangue, P., Payne-Gagnon, J. and Desmartis, M. (2016). m-Health adoption by healthcare professionals: a systematic review. Journal of the American Medical Informatics Association, 23(1): 21220.

Glanz, K., Barbara, R. and Viswanath, K. (2008). Health behavior and health education: theory, research, and practice. 4th ednSan Francisco, CA: Jossey-Bass. 45-51.

Gog, M. (2015). Case study research. International Journal of Sales, Retailing and Marketing, 4(9): 33-41.

Greenhalgh, T., Robert, G., Macfarlane, F., Bate, P., Kyriakidou, O. and Peacock, R. (2005). Storylines of research in diffusion of innovation: A Meta-narrative approach to systematic review. Social Science and Medicine, 61(2): 417-30.

Guiltinan, J. (2009). Creative destruction and destructive creations: Environmental ethics and planned obsolescence. Journal of Business Ethics, 89(1): 19-28.

Hall, V. (1999). The relationship between social support and health in gay men with HIV/AIDS: an integrative review. Journal of the Association of Nurses in AIDS Care, 10(3): 74-86.

Heymann, J., Earle, A., Rajaraman, D., Miller, C. and Bogen, K. (2007). Extended family caring for children orphaned by AIDS: Balancing essential work and caregiving in a high HIV Prevalence nations. AIDS Care, 19(3): 337-45.

Janz, K. and Marshall, B. (1984). The health belief model: A decade later. Health Education and Behavior, 11(1): 147.

Jowett, S. and Armitage, S. (1988). Hospital and community liaison links in nursing: the role of the liaison nurse. Journal of advanced Nursing, 13(5): 579-87.

Kadushin, G. (1996). Gay men with aids and their families of origin: an analysis of social support. Health and Social Work, 21(2): 141-49.

Katz, E., Levin, M. and Hamilton, H. (1963). Traditions of research on the diffusion of innovation. American Sociological Review, 28(2): 237-52.

Kissling, E., Allison, H., Seeley, A., Russell, S., Bachmann, M., Musgrave, D. and Heck, S. (2005). Fisherfolk are among those most at risk to HIV: a cross-country comparison of estimated prevalence and numbers infected. Aids, 19(17): 1939-46.

Kothari, C. R. (2004). Research methodology: Methods and techniques. New Age International.

Lamb, W., Hair, H. and McDaniel, D. (2009). Essentials of marketing. 6th ednInternational student ed. Mason (Ohio): South-Western.

Lane, D., Isenberg, D. and Knoop, C. (2007). Iqbal Quadir, Gonofone, and the creation of grameenphone (Bangladesh). Harvard BusinessSchool Publishing: Boston.

LeBlanc, J. G., Milani, C., De Giori, G. S., Sesma, F., Van Sinderen, D. and Ventura, M. (2013). Bacteria as vitamin suppliers to their host: a gut microbiota perspective. Current Opinion in Biotechnology, 24(2): 160-68.

Lupton, D. (2012). M-health and health promotion: The digital cyborg and surveillance society. Social Theory and Health, 10(3): 229-44.

Mail \& Guardian Africa Business Magazine (2015). http://mgafrica.com/article/2015-06-15-african-youth-accountfor-65-of-the-continents-80-billion-consumer-spending-and-ad-targeting.

Nancy, K. and Marshall (1984). The health belief model: A decade late. Available: https://deepblue.lib.umich.edu/bitstream/handle/2027.42/66877/10.1177_109019818401100101.pdf

National AIDS Control Council of Kenya (2014). Kenya AIDS response progress report 2014: Progress towards Zero.

Nöstlinger, C., Loos, J. and Verhoest, X. (2015). Coping with HIV in a culture of silence: results of a body-mapping workshop. AIDS Res Hum Retroviruses, 31(1): 47-48. Available: 10.1089/aid.2014.0316

Okoth-Okombo, D. (1999). Language and ethnic identity: the case of the Abasuba. Kenya Journal of Sciences (Series C, Humanities and Social Sciences), 5(1): 21-38.

Ørngreen, R. and Levinsen, K. (2017). Workshops as a research methodology. Electronic Journal of E-learning, 15(1): 70-81.

Peltzer, K. and Ramlagan, S. (2011). Perceived stigma among patients receiving antiretroviral therapy: a prospective study in KwaZulu-Natal, South Africa. AIDS Care, 23(1): 60-68.

Rogers, E. (2003). Diffusion of innovations. 5th ednSimon and schuster.

Safdari, R., Shams Abadi, A. R. and Pahlevany, N. S. (2018). Improve health of the elderly people with M-health and technology. Iranian Journal of Ageing, 13(3): 288-99.

Shields, P. and Nandhini, R. (2013). A playbook for research methods: Integrating conceptual frameworks and project management. OK: New Forums Press: Stillwater.

Tufte, P. (2009). Participatory communication a practical guide. Washington, DC: World Bank. 5,6. 